\title{
A COMPARATIVE STUDY OF KNOWLEDGE AND PRACTICES ABOUT PLAQUE CONTROL METHODS AMONG MEDICAL AND DENTAL STUDENTS OF GANDHARA UNIVERSITY PESHAWAR
}

\author{
Gul Sanga Nizam¹, Shariq Ahmad ${ }^{1}$, Baber Ahad ${ }^{1}$, Saira Bano¹, Saira Afridi ${ }^{1}$
}

1. Sardar Begum Dental College

\begin{abstract}
Back ground:

Plaque control methods are one of the most important tools in promoting and improving oral health of an individual. Plaque can lead to the most prevalent oral diseases that are dental caries and gingivitis ${ }^{2}$. The available data on prevalence of dental caries show that Pakistan is a low caries country whereas there is persistently high level of periodontal diseases ${ }^{3}$. Improvement of oral health by healthcare professional is a vital aspect of preventive dentistry ${ }^{1}$.
\end{abstract}

\section{Objectives:}

The aim of the study was to assess and compare the knowledge and practices of medical and dental students of Gandhara University Peshawar about plaque control methods.

\section{Materials and methods:}

In a cross sectional study a total of 386 students were surveyed by using self administered structured questionnaires which covered student's knowledge about plaque control methods, dental attendance and smoking. A total of 265 students responded with fully filled questionnaires out of which 121 were filled by medical students and 144 by dental students.

\section{Results:}

Almost $79.8 \%$ Dental students knew about plaque out of which $78(54.1 \%)$ students thought that is caused by not cleaning the oral cavity and 65(45.1\%) thought that it leads to dental caries. One hundred and thirty nine (96.5\%) students clean their teeth out of which 93(64.5\%) clean their teeth twice a day with a tooth brush. One hundred and eighteen (81.9\%) have visited a dentist before out of which only 49(41.5\%) went for regular checkup. Sixteen (11.1\%) students smoke.

Almost $61.1 \%$ Medical students knew about plaque out of which $41(33.8 \%)$ students thought that it is caused by not cleaning the oral cavity and $37(30.5 \%)$ students thought that it leads to dental caries. One hundred and fourteen (94.2\%) students clean their teeth out of which 69(57\%) clean their teeth twice a day with a tooth brush. Sixty nine (57\%) students have visited a dentist before out of which only 26(37.6\%) students went for regular checkup. Twenty nine (23.9\%) students smoke.

\section{Conclusions:}

It is concluded that there is a marked difference between the knowledge and practices among the medical and dental students, and there is a need to enhance the knowledge of medical student regarding dental attendance. Both need more awareness regarding plaque control methods to have a positive role in the oral health education of their patients and the community.

Key words: Plaque control, dental attendance, tooth brushing, smoking

\section{Correspondence:}

GUL SANGA, Sardar Begum Dental College

Contact: 0344-9290918, Email: info@gandhara.edu.pk

https://doi.org/10.37762/jgmds.1-1.74 


\section{INTRODUCTION}

Plaque control is the regular removal of dental plaque and the prevention of its accumulation on the teeth and adjacent gingival surfaces. Plaque is a major etiology of periodontal diseases and plays important role in causation of dental caries the two of the most prevalent oral diseases ${ }^{2}$. Oral diseases such as dental caries and periodontal diseases excessively burden the people of Pakistan. The available data on the prevalence of dental caries show that Pakistan is a low caries country and high prevalence of periodontal diseases ${ }^{3}$.

Periodontal disease is chronic infection caused by bacteria that accumulate in plaque. Therefore by effective plaque control the prevalence of these diseases can be reduced. Effective plaque control methods that can be carried out by the individual themselves include brushing, flossing, oral irrigation, use of fluoride tooth paste and mouthwashes. Besides individual care professional services for plaque control include scaling, pits and fissure sealants and tooth surface conditioning by laser.

Dental students are an important part of academic dental community as they have a role in oral health promotion and education of the public ${ }^{4}$. However their personal oral health literacy \& behavior provide a significant driving force for their role as oral health advisers ${ }^{1}$.

The first objective of this study was to evaluate knowledge and practices about plaque control methods among the dental students of Gandhara University Peshawar who will be the oral health professionals of future. The second objective was to compare the same behaviors with the medical students of the same university, who will be the future health professionals.

\section{MATERIALS AND METHODS}

The cross sectional study was done in Gandhara University during the months of January and February in year 2011, using self admin istered questionnaire that assessed student's knowledge and behavior about plaque control methods, dental attendance and smoking. The questionnaire was based on standard oral health questions from review of relevant publications and dental literature ${ }^{5}$.

Convenience sampling was used as both the colleges are located on the same campus in Peshawar.. Inclusion criteria for the selection of the subjects were current $1^{\text {st }}$ to final year B.D.S and $1^{\text {st }}$ to final year MBBS. Informed consent and confidentiality was included in the questionnaire's ethical review portion. Some questionnaires were filled on the spot and some were collected later on. Students not returning the questionnaires within a week's time were considered unwilling to participate and were set to be the exclusion criteria. The data was analyzed by SPSS version18 (Statistical Program for Social Sciences).

\section{RESULTS}

A total of 386 students, were surveyed by using self administered questionnaires. A total of 265 students responded with fully filled questionnaires so the response rate was calculated to be $68.6 \%$. Out of the 265 questionnaires 121 were filled by medical students and 144 by dental students.

Results were grouped into four categories: knowledge about plaque, knowledge and behavior regarding plaque control methods, dental attendance and smoking. 


\section{KNOWLEDGE ABOUT PLAQUE}

Almost $79.8 \%$ dental students knew about plaque out of which $54.1 \%$ students thought that plaque is caused by not cleaning the oral cavity. Sixty five $(45.1 \%)$ students thought that it leads to dental caries

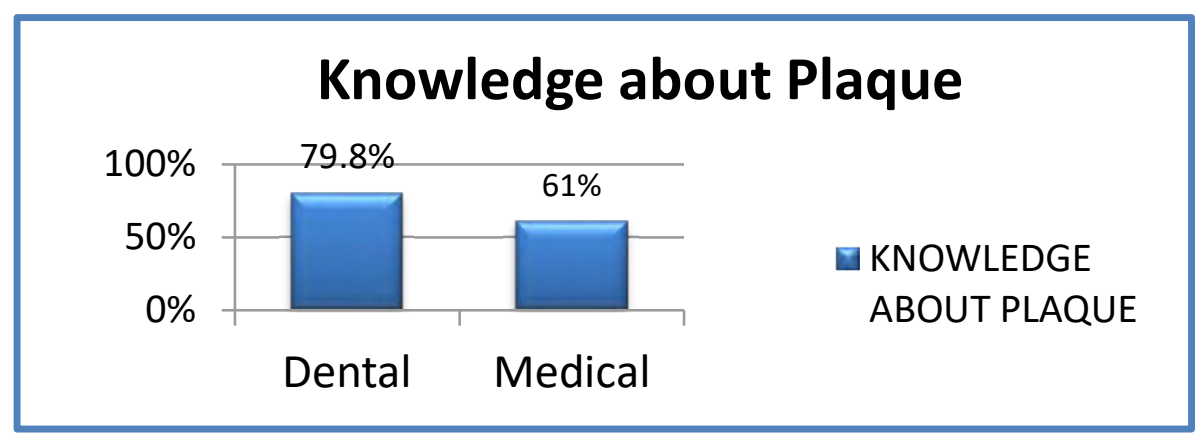

Almost $61.1 \%$ Medical students knew about plaque out of which $41(33.8 \%)$ students thought that it is caused by not cleaning the oral cavity and $37(30.5 \%)$ students thought that it leads to dental caries.

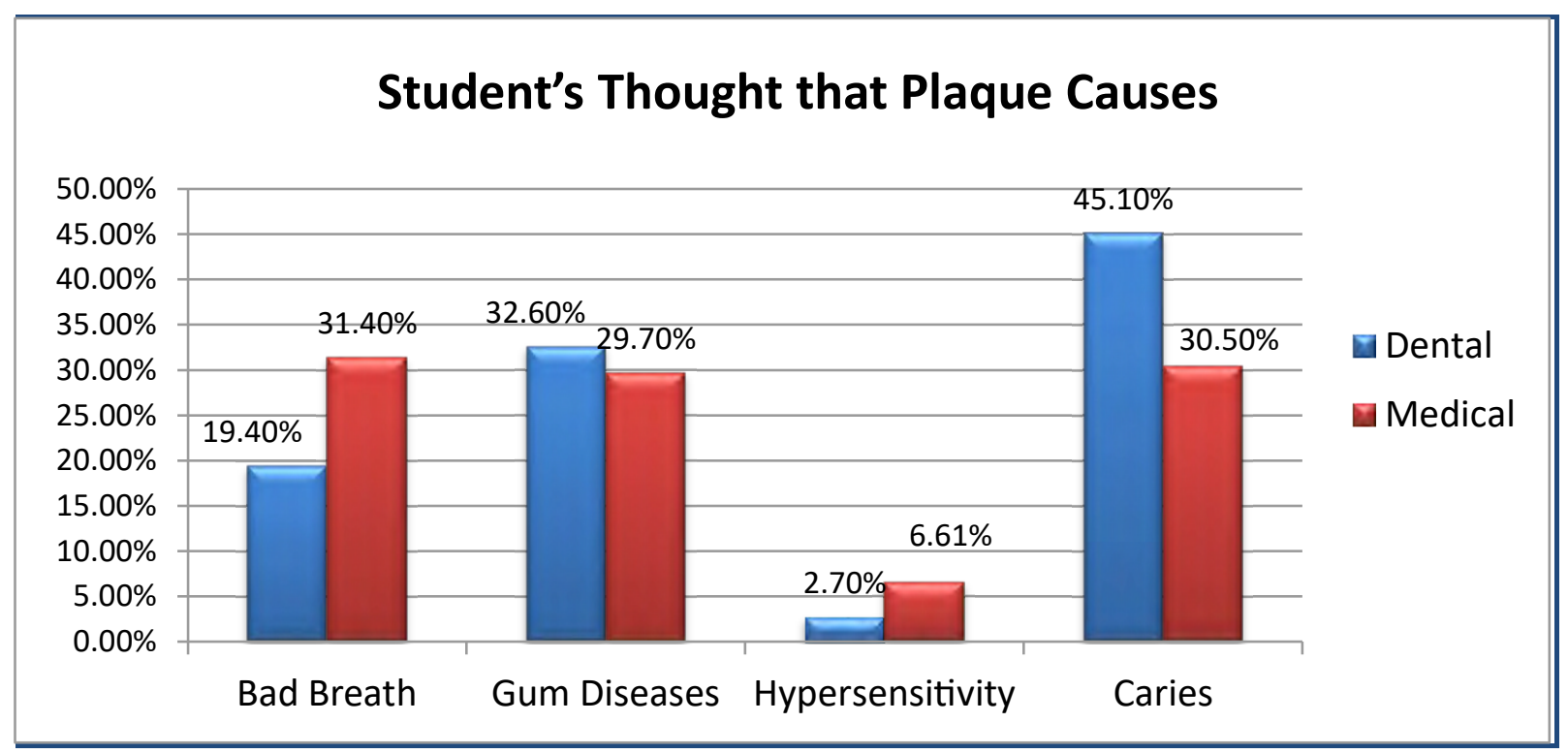


Cleaning of teeth was observed by majority of the students. The data shows that $96.5 \%$ dental students clean their teeth while $94.2 \%$ medical students clean their teeth.

Among dental students $53.9 \%$ brush their teeth after breakfast and before going to bed and among medical students $40.3 \%$ brush their teeth after breakfast and before going to bed. Fifty six point four percent dental students and $50.8 \%$ medical students spent two minutes on brush their teeth. Fifty five point three percent dental students and $49.1 \%$ medical students use soft brush.

Majority of students change their brush after 2 months i.e. $47.4 \%$ dental students and $52.6 \%$ medical students. Knowledge about brushing technique is more in dental students as compared to medical students, $93 \%$ dental students and $70.2 \%$ medical students know the correct brushing technique out of which $50.7 \%$ dental students and $3.5 \%$ medical students were taught by their teachers.

\section{DENTAL ATTENDENCE}

Majority of the dental students had visited a dentist i.e. $81.9 \%$ and only $41.5 \%$ went for regular checkup as compared to $57 \%$ medical students, out of which $37.6 \%$ went for regular checkups.

\section{Dental Attendence}

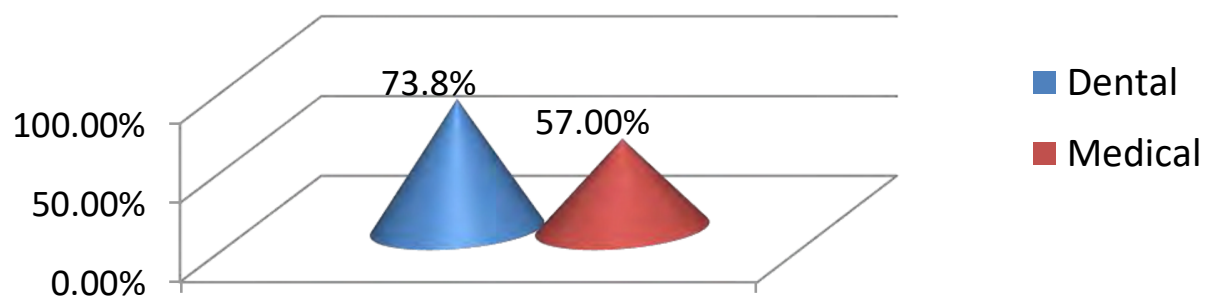




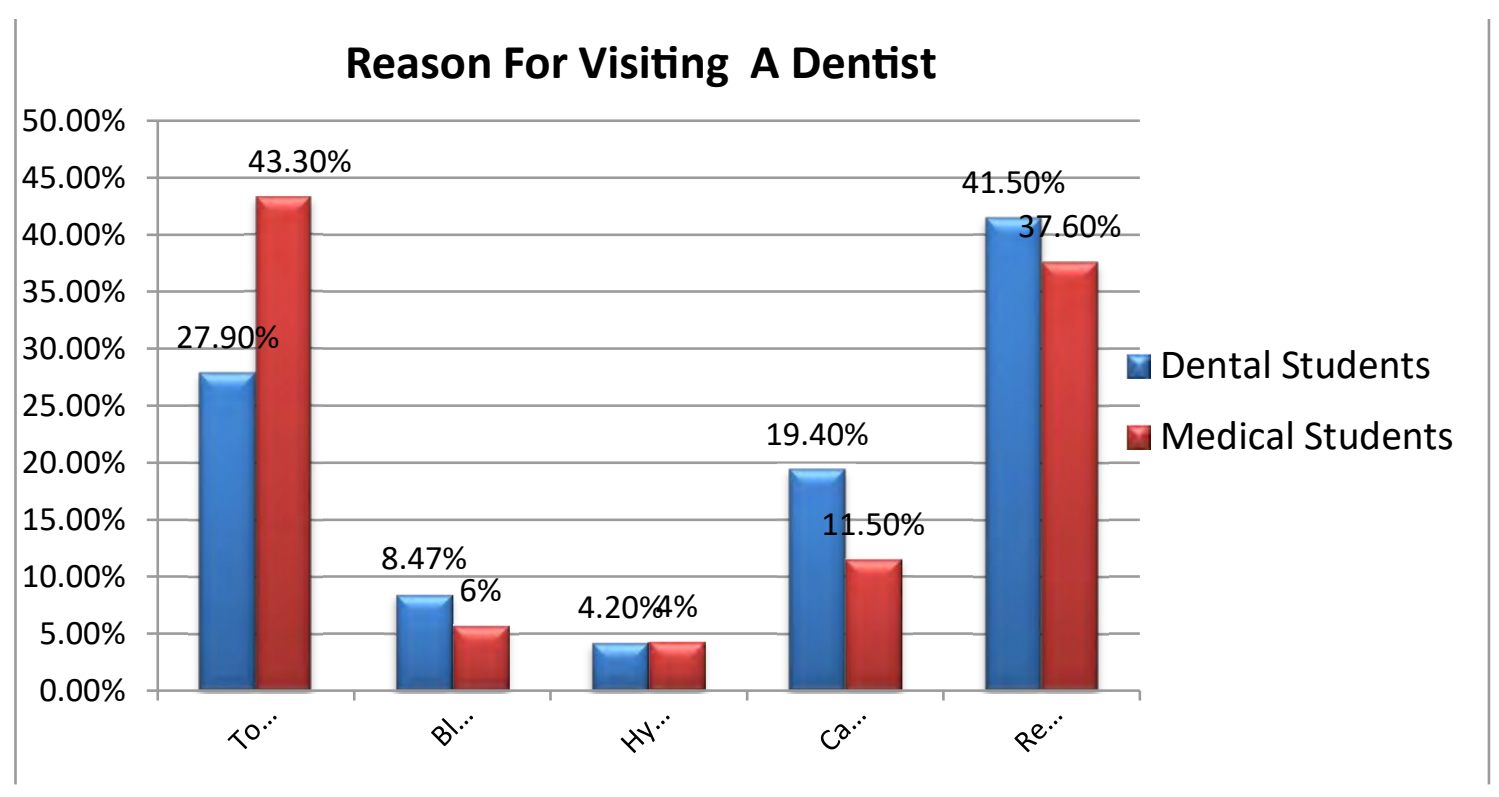

\section{SMOKING}

Twenty three point nine percent medical students smoke whereas compared with dental students only $16 \%$ smoke.

\section{DISCUSSION}

This article reported about the Knowledge and practices about plaque control methods among medical and dental students of Gandhara University Peshawar.

Dental students have more knowledge about plaque and its control methods than medical students. Our study showed that almost $45 \%$ students brush their teeth more than once a day as compared to study conducted in University of Italy in which the result was 92

percent ${ }^{11}$. Majority of the students visited a dentist visited a dentist when they had some dental problem similar to study done in Kuwait ${ }^{12}$. In a study conducted among the students of an Italian University $60 \%$ students used to regularly visit the dentist a much larger number than our study i.e. 41 percent $^{11}$.

Almost $20 \%$ students of the students used to smoke which is less when we compared it with the study done in Koirala Institute of Health Sciences, Nepal, where $38.4 \%$ students smoke tobacco ${ }^{13}$.

\section{CONCLUSION}

It is concluded that there is a marked difference between the knowledge and practices among the medical and dental students, and there is a need to enhance the knowledge of both medical and dental student regarding dental attendance (Regular Visits). Both need more awareness regarding plaque control methods to have a positive role in the oral health education of their patients and the community. 


\section{RECOMMENDATIONS}

To improve oral health behavior of medical students as they are the future role models for their patients, greater emphasis should be placed on oral health related knowledge during their undergraduate training by conducting seminars and workshops to improve their oral care behavior. Comparisons of dental student's oral behavior with students of other profession have been reported ${ }^{9}$.

\section{REFERENCES}

1: Rubinamumtaz, Attaullah and Ayyaz Ali khan. A comparative evaluation of oral health knowledge attitude and practices of dental pharmacy students of Riphah international university. Pakistan oral and dental journal(June 2009) vol 29 no 1.

2: Carranza TN. Clinical Periodontology. Ed $9^{\text {th }}$ W.B Saunders ; 2002.

3: Ayaz Ali Khan. Oral Health in Pakistan a situation analysis. Ministry of Health, Government of Pakistan; 2002

4: Al-omari QD, Hamasha AA.J. Gender-specific oral health attitudes and behavior among dental students in Jordon. comptemp dent pract. 2005; 6(1): 107-110.

5: Syed Hassan bokhari, ayyaz Ali khan. Self-reported oral health related knowledge, attitude and practices among medical doctors of Lahore, Pakistan - a Pilot study. Journal of Pakistan dental association Jan-Mar 2007: vol.16(1).

6: Sunny A.Okeigbemen, Roseline ohre.self reported oral health behavior and perceived treatment needs of dental students in Benin City, Nigeria Pakistan oral and dental journal vol 27(.2): 229-232

7:Hikiji h, Koshikiya N, Fujhara $\mathrm{H}$ et al. changes in the awareness of oral health among new students newly enrolled in at the university of Tokyo over past 15 years.int J Dental Hygiene 2005 ; aug 3(3) 137144

8: AJ Sharda, S Shetty, A comparative study of oral health knowledge, attitude and behavior of rst and final year dental students of Udaipur city, Rajasthan, India. International Journal of Dental Hygiene Nov 2008; $\mathrm{Vol} 6(4):, 347-353$

9: Al-wahdani, AM.Alomiri MK Kawamura M.difference itself reported oral health behavior between dental students and dental technology/dental hygiene students in Jordon J.Oral sci 2004 ;Vol 8(2):98102

10: AJ Sharda, S Shetty, A comparative study of oral health knowledge, attitude and behaviour of nonmedical, Para-medical and medical students in Udaipur city, Rajasthan, India International Journal of Dental Hygiene May2010;pages 101-109.

11. Rimondini L, Zolfanelli B, Bernardi F, Bez C: Self Prevventive oral health behavior in an Italian university student population. J Clin Periodontol 2001; 28:207-211.

12. Al-Hussaini R, Al-Kandari M, Hamadi T, Al Mutawa A, Honkala S, Memon A. Faculties of Medicine and Dentistry, Health Sciences Centre, Kuwait University, Kuwait 2003; Vol. 12(4).

13. Ghimire $A^{1}$, Sharma B, Niraula SR, Devkota S, Pradhan PM. Kathmandu Univ Med J (KUMJ) JanMar2013;11 (41): 32-36. 